\title{
JURISPRUDENCIA PENAL AMBIENTAL \\ (PRIMER SEMESTRE 2018)
}

\author{
ELENA GÓRRIZ ROYO \\ Profesora titular de Derecho Penal \\ Universitat de València. Estudi General \\ MARIA MARQUÈS I BANQUÉ \\ Profesora colaboradora de Derecho Penal \\ Universitat Rovira i Virgili \\ NÚRIA TORRES ROSELL \\ Profesora agregada Serra Húnter de Derecho Penal \\ Universitat Rovira i Virgili
}


Sumario: 1. Delitos relativos a la ordenación del territorio y el urbanismo. 2. Delitos contra los recursos naturales y el medio ambiente. 3. Delitos relativos a la protección de la flora, la fauna y los animales domésticos.

\section{DELITOS RELATIVOS A LA ORDENACIÓN DEL TERRITORIO Y EL URBANISMO}

Durante la etapa a la que se ciñe este comentario, han recaído diversas e interesantes sentencias del Tribunal Supremo en materia de delitos sobre la ordenación del terrorismo y el urbanismo (art.319 CP, apartados 1 y 2º) así como en relación con las prevaricaciones urbanísticas (art. 320 CP).

La primera de ellas es la STS núm. 88/2018, de 21 de febrero, en la que se resuelve el recurso de casación planteado contra la sentencia dictada por la Audiencia Provincial de Valencia (Sección segunda) de 23 de enero de 2017. En esta última se condenó a uno de los acusados C.O. -administrador y socio único de una empresa constructora TSLU-, como autor de un delito continuado contra la ordenación del territorio, con la atenuante muy cualificada de dilaciones indebidas, a la pena de prisión de un año y dos meses con inhabilitación especial para el ejercicio de sufragio pasivo, multa e inhabilitación especial para profesión u oficio por tiempo de un año y seis meses. Asimismo, se condenó al padre del anterior, A. U., alcalde de una localidad valenciana desde el año 1979, en concepto de cooperador necesario de un delito continuado contra la ordenación del territorio, con la atenuante muy cualificada de dilaciones indebidas, a la pena de prisión de un año y dos meses, inhabilitación especial para ejercicio de sufragio pasivo y multa; así como en concepto de autor de un delito continuado de prevaricación urbanística con la atenuante muy cualificada de dilaciones indebidas a la pena de prisión de un año y dos meses, con inhabilitación especial para ejercicio del derecho de sufragio pasivo y multa. Ambos condenados plantearon sendos recursos de casación ante el Tribunal Supremo, donde se cuestionan alguno de los aspectos más polémicos relativos con la aplicación reciente, en sede judicial, de los delitos de los arts. 319.2 y $320.2 \mathrm{CP}$.

Los hechos enjuiciados en primera instancia tuvieron lugar los años 2003 y 2004 , cuando uno de los condenados fue elegido alcalde del municipio valenciano, vendiendo en ese momento las participaciones sociales de la empresa que 
dirigía -TSLU-, a su hijo. Los hechos de la sentencia se apoyan en un acuerdo entre el padre y el hijo para construir -a través de aquella entidad-, viviendas en diversos polígonos del término municipal, en terrenos que tienen la calificación de suelo no urbanizable común, en parcelas inferiores a diez mil metros cuadrados, amparadas en licencias otorgadas en abril del citado año, unánimemente, por el Pleno municipal del Ayuntamiento, tras Decreto provisional con visto bueno del citado alcalde. No obstante éste era conocedor de que el arquitecto técnico municipal tenía reparos sobre la legalidad de las obras. Así se ejecutaron 25 edificaciones en diversas parcelas de aquellos polígonos.

El recurso de casación planteado por el alcalde condenado, cuestiona tres aspectos que podrían vulnerar el art.24.1 y 2 CE y que son desestimados en el FD $1^{\circ}$ de esta sentencia: primero, la falta de prueba sobre el acuerdo con su hijo para llevar a cabo dichas construcciones; en segundo lugar, el conocimiento del carácter "no autorizable" de las construcciones, como elemento típico del delito del art. 319.2 CP; tercero, que las licencias fueron concedidas por el Pleno municipal, y no por el recurrente. Resumidamente, el TS viene a desestimar todos estos motivos, diciendo que a través de la prueba de inferencias se llega a la conclusión de que existe una relación directa entre la adquisición de las participaciones sociales de TSLU por el hijo, y la actividad constructiva de esta empresa en el municipio valenciano, al tiempo que el Pleno Municipal del que forma parte el padre de este, A.U., empieza a conceder licencias urbanísticas para autorizar la construcción en unos polígonos con parcelas de extensión inferior a diez mil metros cuadrados. Respecto del conocimiento del carácter "no autorizable" de dichas construcciones, se entiende probada al admitir el propio recurrente que era consciente de las reservas sobre la legalidad que tenía el arquitecto municipal. En todo caso, se indica que por el hecho de que hubiera parcelas cercanas en similares condiciones no cabe justificar las edificaciones enjuiciadas pues, siguiendo, a nuestro TC se sostiene que el principio de igualdad no da cobertura a un "imposible derecho a la igualdad en la ilegalidad". Por último, frente al argumento de que las licencias no fueron concedidas por el recurrente, a la sazón, alcalde, sino por el Pleno municipal, se recuerda que el tipo del art. 320.2 CP también castiga la conducta de quien resuelve o vota por 
sí solo y lo que, en todo caso consta es que el recurrente en todos los casos votó a favor.

De mayor interés resulta el motivo segundo del recurso de casación del alcalde condenado -y recurrente- referido a la posible vulneración del derecho fundamental al non bis in ídem, derivado del derecho fundamental a la legalidad penal (art. 25.1 CE), en relación con el derecho a la libertad (art. $17 \mathrm{CE}$ ). En concreto porque se entiende infringido lo dispuesto en el art.8 CP, al sustentar el recurrente que se debió aplicar un concurso de normas, entre los delitos por los que se le condena y no un concurso de delitos, como así sucedió. Es decir, según el recurrente se debía haber aplicado la regla de consunción del art.8.3 CP, de modo que el desvalor de la cooperación en el delito urbanístico art. 319.2 CP debió consumirse en el propio de la prevaricación específica "necesariamente dirigida a tal fin". EI TS, no obstante, sostiene que media un concurso delictivo, basándose en anteriores sentencias (vid. STS núm. 12/2009, de 27 de noviembre) donde ya se indicaba que la aplicación del art. 320 junto al 319, no conculca el principio non bis in ídem, "pues no cabe desconocer que el bien tutelado con la sanción penal en la prevaricación administrativa no es sólo la ordenación del territorio sino también la administración pública, como en toda prevaricación administrativa". Asimismo, el TS entiende que el recurrente obvia que de la narración probada se infiere adecuadamente que ambos condenados se pusieron de acuerdo para construir. De modo que concluye que ninguno de los dos delitos por los que fue condenado lleva por sí la acción ni el desvalor del otro. En definitiva, el TS desestima el motivo del recurrente, llegando a la importante conclusión según la cual "no existe un concurso de normas sino de delitos, sin que ninguno de ellos sea medio necesario para la comisión del otro, por lo que concurren en modalidad real".

El único motivo planteado en el recurso y admitido por el TS, se refiere a la violación del principio acusatorio y derecho a la tutela judicial efectiva, (art. 24.1 CE) por haber impuesto la pena de multa del art. 320.2 CP. Es decir, la sentencia condenatoria impuso al acusado A.U., como autor del citado delito de prevaricación urbanística, además de la pena de inhabilitación, pena de prisión $y$ pena de multa. No obstante, el texto vigente en el momento de la comisión de los hechos (años 2003 y 2004) era el original del CP de 1995. Conforme al 
mismo, el art. 320.2 CP preveía las penas de prisión y multa de modo alternativo, no de modo conjunto como se prevé ahora. De modo que al aplicarse la penalidad prevista en la redacción posterior a la reforma de LO 5/2010, la Audiencia le aplicó retroactivamente una legislación más desfavorable. El resto de los motivos alegados por el recurrente son desestimados por el TS, pues éste entiende que las edificaciones eran "no autorizables" y además con respecto a la posible modificación del Plan urbanístico -como norma de complemento- para justificar una aplicación retroactiva favorable, el TS defiende que los delitos del art. $319 \mathrm{CP}$ "se refieren a las normas y normativa vigentes y exigibles en el momento en que se lleva a cabo la acción. Que posteriormente la normativa varíe esas condiciones no afecta a la antijuridicidad de la conducta pasada, ni supone necesariamente una valoración diferente y más benigna de la misma. Lo relevante es la normativa que regía en el momento de los hechos." Así pues se entiende que el delito no desaparece por la intención del Consistorio de proceder a modificar el Plan. Asimismo, se sostiene que la existencia de otras construcciones en las mismas condiciones, no acreditan la legalidad de la realizada por los solicitantes.

Por otra parte, con respecto al recurso planteado por el hijo del anterior acusado, C.O., se desestiman todos los motivos que alega, puesto que, en mayor o menor medida, se remiten a lo ya planteado por el otro recurrente que, asimismo, era su padre. Por todo lo anterior, el TS concluye estimando el recurso de casación planteado por el recurrente A.U., alcalde de la población valenciana, contra la SAP de Valencia, de 23 enero de 2017 (Sección $2^{\circ}$ ) en lo tocante a la pena impuesta por el delito de prevaricación urbanística del art. 320.2 CP. De modo que se dicta una segunda sentencia en la que, respecto de dicho recurrente, se deja sin efecto la pena de multa si bien se mantiene la de prisión de diez meses y de inhabilitación especial para empleo o cargo público por tiempo de ocho años, que conlleva la privación del cargo efectivo de Alcalde electo. Asimismo, se mantiene la condena por el delito del art. 319.2 CP.

La segunda sentencia que interesa analizar es la STS núm. 73/2018, de 13 de enero, que resuelve el recurso de casación planteado contra la SAP de Castellón (Sección 1르), de 3 de enero de 2017, en la que se condena a R., por unos hechos sucedidos entre 2008 y 2010 y, en esencia, consistentes en excederse de la 
licencia concedida para realizar una edificación en suelo no urbanizable común, dentro del Parque Natural de la Sierra Espadán, y que por ello había sido condicionada a lo establecido por el Servicio Territorial de Medio Ambiente. Sin embargo, tras una inspección el 20 de abril de 2010, los agentes del SEPRONA detectaron que la edificación realizada no coincidía ni en volumen ni en superficie con el proyecto básico aportado, pues la planta segunda constaba en el proyecto como diáfana y con tejado a cuatro aguas, cuando en realidad se encontraba distribuida en tres habitaciones: dos aseos, una galería, un salón comedor y dos terrazas, todo ello en construcción; mientras que otra planta tenía casi toda la distribución modificada con tres habitaciones, dos aseos, un salón comedor, cocina, etc. Por la Alcaldía del Ayuntamiento de Sueras se ordenó la suspensión inmediata de las obras mencionadas, al tiempo que se acordaba incoar "el correspondiente expediente de disciplina urbanística". Asimismo, la Consellería de Medio Ambiente procedió a incoar expediente por el que se ordenaba la restauración de la legalidad urbanística. También fueron acusados el alcalde y varios concejales de la citada localidad por los informes emitidos para la concesión de la licencia de estas obras.

No obstante la SAP de Castellón de 3 de enero de 2017, absolvió al alcalde y a los concejales, a la vez que condenó al individuo, R., como autor de un delito contra la ordenación del territorio del 319.1 CP. Esta sentencia fue recurrida tanto por el condenado como por el Ministerio Fiscal, alegando éste último, indebida inaplicación de la medida de demolición prevista en el art. 319.3 CP. Con respecto a los motivos aducidos por el condenado, el TS rechaza el alegato al error de prohibición del art. $14 \mathrm{CP}$, si bien se detiene en analizar el motivo referente al cambio legislativo en el art. 319.1 CP, pues antes de la reforma de LO 5/2010 se aludía a "construcción no autorizada" y ahora se alude a "construcción no autorizable" considerando que esa modificación le debía ser aplicada retroactivamente y que "no autorizable" significaría una exigencia superior a "no autorizada" pues supone que nunca la construcción podrá ser legalmente viable. No obstante, el TS define "no autorizable" como "que la obra ya iniciada o realizada no puede ser reconocida posteriormente como ajustada a la legalidad, lo cual comprende tanto las obras realizadas sin licencia que no sean legalizables, como también las que, contando con licencia, y al margen de 
posibles responsabilidades de haberse obtenido ilegalmente, no eran autorizables". Entiende el TS que el recurrente se equivoca al interpretar este elemento del delito, pues "se refiere a la ilegalidad material de la edificación cuando se realiza, por no ajustarse a la ordenación. No basta que se haya levantado sin licencia; es necesario que sea contraria a la legalidad urbanística vigente en ese momento, lo que excluiría su autorización (no autorizable)". Por otro lado, el recurrente pretende excluir el delito porque no se trataría de una construcción por completo contraria a la licencia, sino un "exceso". No obstante, con buen criterio, el TS recuerda que podrían excluirse del tipo los excesos proporcionalmente reducidos o insignificantes "pero nunca casos como el que aquí examinado de absoluta y patente desviación de los términos condicionados de la licencia".

Por último, el TS examina el motivo alegado por el Ministerio Fiscal y que combatía la decisión de la Audiencia de eludir la orden de demolición de lo indebidamente construido de acuerdo con el art. 319.3 CP. Este es el único motivo admitido por el TS, ante todo, bajo el argumento de que "la reparación en la modalidad de demolición de la construcción ha de ser, por ello, en principio la regla. Es a lo que literalmente obligaría el art. 109 CP”. Asume el criterio de que el art. 319.3 CP no establece la demolición de forma imperativa, si bien acepta una interpretación, ciertamente, debatido, según la cual, las referencias a "en cualquier caso" y "podrán" han de interpretarse como que tanto en el caso del art. 319.1 como en el del $2^{\circ} \mathrm{CP}$, cabe la demolición. Así llega a sostener que "el art. 319.3 no introduce criterio orientador alguno para adoptar una u otra decisión. Han de ponderarse factores como la gravedad del hecho y la naturaleza de la construcción; la proporcionalidad de la medida en relación con el perjuicio que causaría al infractor; comprobar si están implicados sólo intereses económicos, o también derechos fundamentales como el uso de la vivienda propia. Asimismo puede atenderse a la naturaleza de los terrenos en que se lleva a cabo la construcción (especial protección, destinados a usos agrícolas, etc.)". Sobre la base de este razonamiento considera que no hay motivos para posponer la medida de demolición que se revela como procedente en el caso de autos. Así pues, el TS falla estimar el recurso de casación interpuesto por el Ministerio Fiscal contra la SAP de Castellón de 3 de enero de 2017, dictando una 
segunda sentencia en la que se decreta la demolición de lo indebidamente construido en los términos anteriormente indicados.

La última de las sentencias que conviene traer a colación es la STS núm. 830/2017, de 18 de diciembre, en la que se resuelve el recurso de casación contra la SAP de Madrid, de 30 de noviembre de 2016, en la que se condena al acusado como autor de un delito del art. 319.2 CP y se acuerda la demolición de las obras por la Administración competente. Los hechos enjuiciados tuvieron lugar en 2013, en la segunda fase de un camping, sito en el término municipal de Aldea del Fresno (Madrid). Así, durante una inspección llevada a cabo por agentes de la Policía Local se descubrió que se estaba efectuando el cerramiento de una parcela mediante un muro de bloques de hormigón con dos lados, convergentes en la puerta de entrada, que enlazaban por los extremos opuestos con otro muro, previamente construido, lindante con la plaza contigua. El cerramiento y la jardinera fueron realizados por encargo del titular de la parcela, el acusado H., quien, además, en fecha no determinada, no anterior a 2011, había solado la plaza de camping con losetas (o encargado hacer tal trabajo a un tercero), abarcando una extensión de 300 metros cuadrados. En fechas anteriores a 2009, el acusado también había realizado ordenado realizar, en la plaza de camping citada, diversas construcciones (básicamente una casa prefabricada, caseta rectangular, muro...). El acusado había realizado las obras mencionadas a sabiendas de que no habían sido autorizadas, ni podían serlo de acuerdo con las Normas Subsidiarias de Planeamiento Municipal en las que se clasificaba el terreno como suelo no urbanizable, estando legalmente prohibida la realización de obra alguna, así como la edificación o instalación de cualquier elemento fijo o permanente. Además, el suelo sobre el que se realizaron las obras estaba enclavado en la zona a la que se refiere la Orden 903/2001, de 5 de abril, de la Consejería de Medio Ambiente de la Comunidad de Madrid, por la que se declara la iniciación del procedimiento de tramitación del Plan de Ordenación de los Recursos Naturales de la Zona de Especial Protección de las Aves Silvestres denominada "Encinares de los ríos Cofio y Alberche". Tras la inspección de la Policía Local de fecha 6 de noviembre de 2013, el acusado solicitó licencia para el vallado de la plaza de camping al Ayuntamiento de Aldea del Fresno, no siendo esta concedida por no permitirlo la normativa urbanística 
aplicable, si bien la notificación de esa imposibilidad de concesión se produjo con posterioridad al 10 de marzo de 2014, sin que conste que después de dicha notificación continuasen las obras.

En el recurso de casación, entre otros motivos, el condenado, alega que no ha tenido dolo y no es responsable del delito que se le ha imputado. Respecto a estos argumentos, el TS contesta que consta como probado, en el relato fáctico, que el acusado emprendió todas las obras antes mencionadas a sabiendas de que no habían sido autorizadas. Además, el acusado sí podía ser autor responsable de los hechos, en concepto de "promotor" porque según el TS, por tal hay que entender "cualquier persona, física o jurídica, pública o privada, que, individual o colectivamente, impulsa, programa o financia, con recursos propios o ajenos, obras de edificación para sí o para su posterior enajenación". Por otra parte, el recurrente alega que no existió prueba suficiente para desvirtuar el derecho a la presunción de inocencia. Y ello porque no ha podido acreditarse la existencia de dolo o intención por parte del acusado, aunque concurran los elementos objetivos del delito. Entiende que lo que hizo era algo generalizado en los 470 propietarios de las parcelas. Frente a ello, el TS sostiene que la sentencia declara probado que el acusado emprendió las obras a sabiendas de que no habían sido autorizadas ni podían serlo. Así pues, se indica que el acusado admitió en el plenario que tenía conocimiento de la situación urbanística del terreno antes de emprender las obras; que sin ese reconocimiento la actuación dolosa del acusado estaba acreditada ya que emprendió la construcción sin solicitar licencia; y que, como mínimo, el acusado se colocó en una situación de ignorancia deliberada ya que poseía la plaza de camping desde hacía más de veinte años y necesariamente debía de estar al tanto de una situación urbanística notoria. Es interesante destacar que aquella situación de "ignorancia deliberada" es admitida por el TS para confirmar la conducta dolosa seguida por el recurrente. Por todo ello el TS rechaza este último motivo alegado por el recurrente. Con respecto a los motivos del recurso planteado por el Ministerio Fiscal, el TS tampoco los admite, pues básicamente, se oponía a que la sentencia de la Audiencia condenara al acusado como autor de un delito contra la ordenación del territorio del art. 319.2 CP, pero no de los arts. 319.1 y 338 CP. El Ministerio Fiscal estimó que, teniendo en cuenta la normativa vigente, 
el lugar en el que tuvieron lugar los hechos era una zona de Especial Protección y, por lo tanto, que procedía la aplicación de los preceptos indicados. No obstante, el TS no admitió este motivo del recurso sobre la base de que en ningún momento el relato fáctico establecía que los hechos tuvieran lugar en "Zona de Especial Protección" como pretendía el Ministerio Fiscal, que entendía aplicable el supuesto agravado del art. 319.1, en relación con el art. 338, ambos del CP. En consecuencia, el TS llegó a la conclusión de que "la resolución recurrida, dictada por la Audiencia, ha considerado que los hechos eran constitutivos de un delito contra la ordenación del territorio del art. 319.2 CP por haberse llevado a cabo las obras en 'suelo no urbanizable', pero que no resultaban de aplicación los arts. 319.1 y 338 CP porque el suelo no tenía la condición de 'espacio natural protegido' al haberse decretado la nulidad del Decreto 36/2010 dictado por el Consejo de Gobierno de la Comunidad Autónoma." Sobre la base de los anteriores fundamentos jurídicos, finalmente, el TS desestimó tanto el recurso planteado por el condenado, como por el Ministerio Fiscal contra la SAP de Madrid, de 30 de noviembre de 2016.

\section{DELITOS CONTRA LOS RECURSOS NATURALES Y EL MEDIO AMBIENTE}

En el periodo temporal de referencia de esta crónica, son cuatro las resoluciones jurisprudenciales relativas a los delitos contra el medio ambiente susceptibles de comentar. Dos de ellas relativas a supuestos de contaminación acústica y las otras dos a supuestos de vertidos.

La primera sentencia relativa a contaminación acústica es la SAP de Cáceres (Sección $2^{a}$ ) núm. 308/2017, de 16 octubre, que estima parcialmente el recurso de apelación interpuesto contra la sentencia dictada por el Juzgado de lo Penal de Plasencia, de fecha 12-06-2017, en el único sentido de modificar la pena impuesta a tres de los condenados. La sentencia de instancia condenaba a tres de los acusados, todos ellos regentes de un bar musical en distintos periodos, por un delito de contaminación acústica en concurso ideal con un delito de lesiones, y a dos alcaldes sucesivos de la localidad, por un delito de prevaricación en su modalidad de comisión por omisión, previsto y penado en el art. $329 \mathrm{CP}$. 
Los hechos describen la emisión de ruidos por encima de los valores permitidos durante varios años por parte de un bar musical, con especial incidencia en el domicilio de la denunciante. A lo largo de estos años se sucedieron hasta tres personas en la regencia del negocio y la actividad del local llegó a ser suspendida en más de una ocasión, después de múltiples denuncias y mediciones acústicas. Con relación al delito de contaminación acústica del art. $325 \mathrm{CP}$, la Sala sostiene, como hace la Sentencia apelada, que las obras llevadas a cabo por la primera titular del local no habrían producido el resultado esperado, pudiéndose afirmar la concurrencia de los elementos del tipo.

En concreto, la Sala entiende que "la consumación de estos delitos contra el medio ambiente se produce en el momento en que se verifica el acto de contaminación que infringe la normativa medioambiental, constatando que en tal situación existe una posibilidad de perjuicio grave para el medio ambiente o para las personas. En los distintos supuestos que se han analizado en el presente procedimiento, y sobre la base de las pruebas practicadas, el Juzgador a quo estimó, y así lo comparte también esta Sala, que el delito contra el medio ambiente por contaminación acústica se había consumado desde el momento en que se produjeron las emisiones de ruido, las cuales además no se vieron suprimidas ni cesaron tras las obras que en su día se realizaron por la primera de las personas acusadas. Nos encontramos ante lo que la doctrina conoce como delitos de acumulación, que responden a una repetición acumulativa de actos que producen el riesgo exigido por el tipo".

Con relación al elemento subjetivo, la Sala estima su concurrencia, al menos a título de dolo eventual, por parte de los tres regentes del local. Con relación a la primera titular, se afirma que "la sucesión posterior (a las obras) de reiteradas quejas, unidas a las comprobaciones que la Policía Local efectuó in situ, vienen a corroborar cuanto decimos, sin que la acusada pueda alegar que desconocía la situación, no habiéndose adoptado otras medidas ulteriores para corregir definitivamente el tema".

En la misma línea, se pronuncia con relación a los dos sucesivos regentes del local. Así, en cuanto al segundo regente, afirma: "Cierto es que durante este período de explotación del establecimiento no se realizan mediciones ni hay 
actividad administrativa encaminada a efectuar comprobaciones específicas acerca de la idoneidad del local, pero también que la situación, insistimos, era la misma que cuando fue suspendida su actividad anteriormente, tras el dictamen que efectuó el SEPRONA y al que, sin perjuicio de las controversias sobre el método utilizado, otorgó valor y relevancia el Juzgador, que recoge en la Sentencia de forma detallada sus conclusiones. Que había ruidos y vibraciones, es un hecho objetivo que los agentes recogen en sus informes, pues se personaron en la vivienda y lo apreciaron in situ, dejando constancia de que el volumen de la música era perfectamente perceptible y no permitía conciliar el sueño. En tales circunstancias, y advertido reiteradamente el titular del establecimiento, su actitud pasiva y de dejar pasar, amparándose en la tolerancia municipal, no puede eludir su responsabilidad en las circunstancias que ya exponíamos a propósito de la Sra. Joaquina, habida cuenta del contenido que exige el dolo en este tipo de infracciones. Y, en la misma línea, con relación al tercer y último de los regentes acusados, sostiene: "El delito se siguió cometiendo, al margen de la fecha en que luego el Sr. Aureliano solicitara el cambio de titularidad a favor de un tercero; y en su conducta también existirá dolo, cuanto menos eventual, ya que era sobradamente consciente de los riesgos que se derivaban de la actividad desarrollada en las condiciones en que ésta tenía lugar, siendo numerosos los avisos y advertencias que se le hicieron. Abundando en lo ya expuesto respecto de este requisito, recuérdese que obra con dolo el que conociendo el peligro generado con su acción no adopta ninguna medida para evitar la realización del tipo (STS 327/2007, de 27 de abril y $713 / 2014$, de 22 de octubre )".

La Sala recuerda, además, que "cuando se trata de contaminaciones acústicas, como es el caso, tanto la Jurisprudencia del Tribunal Europeo de Derechos Humanos como la del Tribunal Constitucional ponen de manifiesto las graves consecuencias que la exposición prolongada a un nivel elevado de ruidos tienen sobre la salud, integridad física y moral de las personas, su conducta social, así como en determinados casos de especial gravedad, aun cuando no pongan en peligro la salud de las personas, pueden atentar contra su derecho a la intimidad personal y familiar, en el ámbito domiciliario, en la medida que impidan o dificulten gravemente el libre desarrollo de la personalidad, resaltando que 
constituyen supuestos de especial gravedad cuando se trata de exposición continuada a unos niveles intensos de ruido".

Sobre esta base argumentativa, se rechazan también las alegaciones de los tres apelantes que fueron gerentes del local para negar la concurrencia del delito de lesiones por el que todos ellos fueron también condenados en primera instancia: "Si hemos dicho que quedaba acreditada la concurrencia de los requisitos y presupuestos del delito de contaminación acústica, y por ende, también el elemento subjetivo, del mismo modo habremos de afirmar indiscutiblemente relacionada la producción de ese resultado (de lesiones) con quienes eran conocedores, cuanto menos, de la eventualidad de su producción".

La sentencia confirma también la condena a los dos acusados que ostentaron la condición de sucesivos Alcaldes de la localidad por un delito de prevaricación, previsto y penado en el art. 329 del Código Penal en relación con los artículos 404 y 11.2 del mismo cuerpo legal. Con relación al primero de ellos, la Sala estima que éste "debía asegurarse de que el local reunía las condiciones precisas para poder reiniciar su actividad con seguridad y sin riesgo, efectuando las obligatorias comprobaciones, lo que comenzaba por el propio control de las obras que se realizaron en el inmueble. Es evidente que ello no se produjo, al no ajustarse su realización a los procedimientos correspondientes (presentación de proyecto, obtención de licencia, etc.), no adoptándose las garantías necesarias de que todo era correcto, a través de la inspección por el Arquitecto Técnico Municipal, al menos sobre la efectiva realización de las obras, su sujeción a proyecto, en su caso, y especialmente, que éstas eran idóneas para conseguir la finalidad pretendida (insonorizar definitivamente el local). Entendemos que la realización o no de mediciones por unos u otros técnicos, si bien ciertamente vendría a ser útil para completar el aseguramiento de que los trabajos habrían resultado eficaces, no será sin embargo determinante para eludir la responsabilidad municipal, pues se permitió abrir el local a riesgo y ventura, al considerar que era la opción más adecuada".

La Sala hace especial hincapié en la existencia de un pronunciamiento previo del mismo Tribunal, el Auto de 16 de noviembre de 2012, por el que ya se llamaba la atención sobre esta misma situación y se instaba al Ayuntamiento a 
actuar. Con base en los hechos acaecidos, minuciosamente detallados en la sentencia, la Sala estima que la situación por parte de la autoridad municipal fue de absoluta pasividad tras la última reapertura acordada en 2010, extendiéndose tal pasividad al período en que el segundo de los acusados ostentó la condición de Alcalde.

En este sentido, la sentencia recuerda que "la acción típica (del delito de prevaricación) viene integrada, no solo por conductas activas (por ejemplo, informar favorablemente), sino también omisivas (como silenciar infracciones normativas de carácter general con ocasión de sus inspecciones o simplemente no actuar cuando debiera hacerlo según su competencia). El tipo específico encierra en sí el contenido de la prevaricación genérica, lo que nos lleva a la posibilidad de admitir la comisión por omisión. Es cierto que las otras dos modalidades concretas de prevaricación funcional, en materia de ordenación del territorio y patrimonio histórico, no contemplan, de manera expresa, la comisión omisiva, pero no se puede olvidar que, la prevaricación omisiva, ha sido admitida por la Sala Segunda del Tribunal Supremo en Acuerdo General de 30 de junio de 1997, por lo que no existe obstáculo para acudir a la cláusula general del artículo 11 del Código Penal. La modalidad de prevaricación omisiva ha sido admitida por la jurisprudencia del Tribunal Supremo y adquiere todavía una mayor justificación y razonabilidad en los casos de actuaciones de los funcionarios responsables en actuaciones medioambientales. Como tal delito de infracción de un deber, éste queda consumado en la doble modalidad de acción o comisión por omisión, cuando ignora y desatiende la aplicación de la legalidad, convirtiendo su actuación en expresión de su libre voluntad y, por tanto, arbitraria, que no siempre exige un efectivo daño a la cosa pública o servicio de que se trate. Dicho daño está constituido por la quiebra que en los ciudadanos va a tener la credibilidad de las instituciones y la confianza que ellas debe merecerle, porque, como custodios de la legalidad, son los primeros obligados, y esta quiebra puede producir efectos devastadores en la ciudadanía, pues nada consolida más el estado de derecho que la confianza de los ciudadanos en que sus instituciones actúan de acuerdo con la Ley y que por tanto, el que se aparta de la norma recibe la adecuada sanción que restablece aquélla confianza rota (Sentencia de 22 de mayo de 2.001)". 
Además de citar jurisprudencia en el mismo sentido de la Sala $2^{a}$ del Tribunal Supremo, la sentencia ahora comentada incide en la responsabilidad de las autoridades municipales recordando la jurisprudencia de la Sala $3^{\underline{a}}$ del Tribunal Supremo que pone especial énfasis en la competencia local cuando se trata de ruidos. Así, afirma: "La Sala $3^{\text {a }}$ expresa que el tema es competencia de todos los poderes públicos, paro sobre todo 'los Ayuntamientos... tienen que mostrarse particularmente rigurosos en este problema de respeto al medio ambiente, acústico entre otros'. Añade además la Sala $3^{\underline{a}}$, que se trata de un tema ambiental en el que hay que poner, por consiguiente, especial cuidado: 'En este problema de respeto por el medio ambiente, los poderes públicos tienen que mostrarse particularmente rigurosos... pues muchos de sus aspectos afectan a la supervivencia, y otros, como el de la contaminación acústica, a la salud y a la convivencia civilizada'".

Como se ha indicado más arriba, la sentencia comentada estima parcialmente el recurso de apelación interpuesto contra la sentencia de instancia, en el único sentido de rebajar la pena impuesta a los tres condenados por el delito de contaminación acústica en concurso ideal con un delito de lesiones. Ello se debe a la aplicación de la ley penal más beneficiosa, de acuerdo con la Disposición Transitoria Primera de la LO 1/2015. La conducta delictiva se produjo a lo largo de un amplio intervalo temporal, que comprende, al menos desde el momento de las primeras quejas de la denunciante, en 2004, hasta la suspensión cautelar de junio de 2014. Ello implica que durante la explotación del bar por la primera de las titulares del negocio, la conducta de acumulación de los hechos habría quedado sometida tanto a la ley penal resultante de la reforma de 2003 como a la resultante de la reforma de 2010, y que mientras el local fue regido por los otros dos acusados, la norma en principio aplicable sería la que entró en vigor el 23 de diciembre de 2010. La sentencia de instancia aplicó a todos los casos la normativa más antigua, que preveía una pena de prisión de seis meses a cuatro años y multa de ocho a veinticuatro meses, así como inhabilitación especial de uno a tres años, contemplando un subtipo agravado (imposición de la pena en su mitad superior), si se constataba un riesgo de grave perjuicio para la salud de las personas.

Sin embargo, entiende la Sala que en la medida que se está aplicando el tipo 
básico y se excluye el resto de modalidades agravadas y, específicamente, la de riesgo de grave perjuicio para la salud de las personas, la normativa más favorable es la que resulta de la aplicación de la vigente regulación legal (fruto de la reforma de 2015), que para la conducta contemplada en el art. 325.1 CP, recoge penas mucho menos gravosas que las regulaciones precedentes. De esta manera, esta sentencia es otro ejemplo de lo que en la crónica anterior ya calificamos como "impacto regresivo" de la reforma de 2015 en la efectiva protección penal del medio ambiente.

Todavía con relación a la penalidad, la Sala estima las alegaciones que se efectúan en los recursos de los tres regentes del bar, en el sentido de exigir una mayor concreción e individualización de las penas en función del grado de participación en los hechos los distintos acusados, debiendo tener tal circunstancia reflejo en la extensión de aquéllas (la condena impuesta a los tres responsables del local había sido la misma para todos: idénticas penas privativas de libertad, idénticas multas e inhabilitaciones). Con relación a los alcaldes, sin embargo, la Sala considera que "el hecho de que ambos resulten condenados en los mismos términos, no supone ningún tipo de inadecuada individualización, pues en definitiva, a ambos se les ha considerado responsables de idénticas conductas, cada una en el marco de sus respectivos mandatos al frente del Ayuntamiento". Finalmente, respecto a la cuota diaria fijada para la pena de multa, la sentencia estima que "no aconteciendo circunstancias extremas para imponer la cuantía mínima prevista en la Ley, pues no cabe en modo alguno presumir la indigencia de los recurrentes, se entiende que la fijación de la cuota diaria en diez euros, situada en una franja muy próxima al mínimo, es adecuada". Recuerda, además, que de acuerdo con la jurisprudencia del Tribunal Supremo, la fijación de una cuota cercana a la cuantía mínima no precisa de una especial motivación.

La segunda de la sentencias sobre contaminación acústica es la SAP de Granada (Sección 2a) núm. 566/2017, de 21 de noviembre, que revoca la sentencia de primera instancia respecto a la condena por un delito de contaminación acústica, manteniendo la condena por tres delitos leves de lesiones. La estimación parcial del recurso de apelación se fundamenta en la vulneración del principio de presunción de inocencia, por haberse dictado "sin el 
respaldo de pruebas de cargo, válidas y practicadas con las garantías necesarias, y de las que quepa inferir razonablemente la concurrencia tanto de los hechos constitutivos de la infracción, esto es los elementos tanto objetivos como subjetivos requeridos por el tipo penal, así como también la participación del acusado en el delito imputado". Concretamente, la falta de prueba se considera con relación a la acreditación del ruido. De acuerdo con la Sala, "la contravención que marca los límites entre el derecho administrativo sancionador y el derecho penal, exige datos objetivos de la infurción mediante procedimientos de medición del ruido artificial y ese dato esencial no puede el derecho penal tolerar que se deje en manos de subjetivas sensaciones o estimaciones sin ningún valor ni criterio fidedigno ni objetivo". La Sala sostiene, como ya había hecho en una sentencia anterior de 16 de marzo de 2015, que si bien la falta de mediciones objetivas y técnicas de valoración supone un impedimento insuperable para la condena por el delito de contaminación acústica, "no impide la condena por lesiones ante un abrumador bagaje incriminatorio a la vista de los historiales clínicos y dictámenes periciales de todo punto convincentes".

En materia de vertidos, la primera sentencia a comentar es la SAP de Murcia (Sección $2^{a}$ ) núm. 431/2017, de 1 de diciembre, que absuelve a distintas personas, todas ellas autoridades, por un delito contra el medio ambiente por los vertidos de aguas no tratadas al río Segura como consecuencia del incumplimiento de la obligación de depuración y tratamiento por parte de la empresa municipal que, desde la década de 1980, tenía atribuida esa competencia en la ciudad de Murcia. Cabe destacar que la absolución se debe a la apreciación de dos cuestiones previas. En primer lugar, la Sala aprecia prescripción del delito con relación a la mayoría de los acusados. La calificación jurídica del Ministerio Fiscal y de las acusaciones lo era por un delito del tipo básico del delito contra el medio ambiente del art. 325 que, en el año 2000, tenía señalada una pena máxima de prisión de cuatro años, por lo que según el art. 131 vigente en esa época, prescribiría a los cinco años. Examinada la causa, la Sala considera que la misma sufrió una paralización de más de cinco años, por lo que ese delito estaría prescrito para cuatro de los acusados, quedando únicamente como perseguible un eventual delito de prevaricación ambiental del art. 329 (prescribiría a los diez años), imputado únicamente a uno de los 
acusados.

Pero, además, la resolución exculpatoria es consecuencia - con efectos para todos los acusados- de la alegación de las defensas de la existencia de una causa general (con afectaciones al derecho al Juez predeterminado por la Ley) que provocaría la nulidad del procedimiento. Como sintetiza la sentencia, "En definitiva, una concreta denuncia contra la actuación de la empresa responsable del tratamiento de aguas urbanas en la ciudad de Murcia y del propio Ayuntamiento (cuando los eventuales responsables eran muy fácilmente identificables y debieron ser las personas contra las que se debió seguir la causa), dio lugar a abrir una investigar general sobre la gravísima situación de las aguas del río Segura afectadas por una intensa contaminación desde hacía décadas y sobre la generalidad de los vertidos, en Murcia y fuera de Murcia. Pero ello, no sirvió para determinar quiénes eran los eventuales responsables de los vertidos en la ciudad de Murcia, sino para imputarla a quienes en la época de la incoación, ejercían responsabilidades en la empresa municipal de aguas de Murcia, en otro ayuntamiento, en la Confederación Hidrográfica del Segura y hasta en una empresa que efectuaba obras públicas en el cauce. Como han alegado algunas de las defensas, en vez de procederse a la investigación de quienes eran los máximos responsables de los vertidos de aguas residuales en el municipio Murcia (la propia Sentencia firme de la Sección Séptima (con sede en Elche) de la Ilma. de la Audiencia de Alicante de catorce' de diciembre de 2007 afirmaba respecto al río Segura que se encontraba en un "grave estado de contaminación, fundamentalmente por la elevada concentración de materia orgánica en descomposición, debida en un $70 \%$ a la falta de depuradora en la ciudad de Murcia"), y que contribuían de forma notable a esa catastrófica situación medioambiental, se procedió a iniciar una investigación que afectó a otros partidos judiciales (Alguazas se encuentra en el partido de Malina de Segura y, el río Mula (afluente del Segura), no pasa por ningún municipio perteneciente al partido judicial de Murcia), por lo que no cabe si no estimar las alegaciones de las defensas en cuanto a que nos encontramos ante una causa general, estimando la cuestión previa y procediendo a declarar la exculpación de los acusados (lo que implica asimismo la ausencia de responsabilidad civil subsidiaria, aunque también cabría indicar que asumidas por las acusaciones 
populares las conclusiones y calificación del Ministerio Fiscal, ninguna pretensión se dirigía ya frente a la Confederación Hidrográfica del Segura)".

A pesar de la absolución por las razones esgrimidas, la Sala considera que no puede dejar de hacer algunas consideraciones "a la vista de la trascendencia de la causa y la extrema gravedad de la situación inicialmente denunciada en su día". Así, la Sala deja constancia de la previsión constitucional con relación al medio ambiente y de algunos documentos internacionales (como por ejemplo, en el marco de las Naciones Unidas, la Declaración de Estocolmo sobre el medio ambiente humano de 1972) y lamenta que la situación del río Segura no se compadeciera con el contenido de los mismos. Considera "inaudito que tuviera que llegarse a ese estado de desastre ambiental, calificado en diversas ocasiones como 'cloaca a cielo abierto', y a la incoación de diversos procedimientos judiciales (en muchos casos, a instancias de particulares y entidades de la Sociedad Civil), para proceder a revertir la situación padecida por vertidos de todo tipo en cientos de kilómetros del río Segura y de sus afluentes".

La última sentencia a comentar es la Sentencia del Juzgado de lo Penal de Valencia núm. 398/2017, de 20 de septiembre, que condena al Alcalde y al Concejal delegado de urbanismo y servicios municipales de un Ayuntamiento, como responsables en concepto de autores de un delito contra los recursos naturales y el medio ambiente en la redacción vigente en la fecha de los hechos, introducida por la reforma de la LO 15/2003, anterior a la modificación operada por la LO 5/2010, de 22 de junio, por ser más beneficiosa para los acusados dada la extensión de las penas previstas. Los hechos probados se refieren a los vertidos de aguas fecales procedentes de una urbanización. La urbanización carecía de una red funcional de alcantarillado, como resultado de un diseño y ejecución deficientes, del desgaste propio de este tipo de instalaciones y de un mantenimiento muy precario, lo que generaba varios vertidos y derrames incontrolados y continuos de aguas fecales procedentes de las diversas áreas de la urbanización, tanto en el cauce de los Barrancos delimitados por la orografía de la urbanización como en determinadas parcelas particulares. Tales vertidos constituían la mayor parte de las aguas fecales generadas en la urbanización, ya que no eran recogidos por colector alguno que los condujese a 
la pertinente depuración.

La sentencia hace una exposición exhaustiva de los hechos acaecidos y declarados como probados con el fin de argumentar la responsabilidad penal de los acusados por un delito contra el medio ambiente en comisión por omisión, con base en el art. 11 a) del CP. Los vertidos, que suponían un grave riesgo para el equilibrio de los sistemas naturales y la salud de las personas, se consideran imputables a ambos acusados porque, siendo ellos quienes tenían legalmente la competencia para ejecutar la red de alcantarillado y conociendo la situación, no lo hicieron durante todo el período que abarcó su mandato.

\section{DELITOS RELATIVOS A LA PROTECCIÓN DE LA FLORA, LA FAUNA Y LOS ANIMALES DOMÉSTICOS}

En lo que atañe a los delitos relativos a la protección de la flora y la fauna y los animales domésticos (arts. 332 a 337bis CP) destacamos las siguientes resoluciones.

En primer lugar, la SAP de Teruel 3/2018, de 29 de enero, analiza el alcance de los arts. 335.2 y .4 CP atendiendo a la redacción del precepto anterior a la LO 1/2015, puesto que los hechos examinados se cometieron en el año 2014. La sentencia subraya las discrepancias interpretativas surgidas en la determinación del objeto material del delito, discrepancias que no derivan sino de una falta de taxatividad y de claridad en el tipo penal. En concreto, la problemática surge a partir de la doble remisión efectuada en el art. 335.2 CP hacia el art. 335.1 y, ulteriormente, al art. $334 \mathrm{CP}$ en relación con las especies objeto de caza. En este sentido se plantea si tal objeto material se concreta en las especies no amenazadas y cuya caza estuviera prohibida o bien en especies no amenazadas pero cuya caza pudiera ser autorizada. La interpretación resulta relevante en el caso concreto, en que los hechos enjuiciados dan cuenta de cómo los acusados abatieron una "cabra hispánica", esto es, una especie cinegética susceptible de ser pieza de caza con la debida autorización, pero sin contar los acusados con el correspondiente permiso. El tribunal sostiene que el tipo requiere la prohibición de la caza y argumenta que la posterior reforma de 2015 en la que el legislador ha modificado el art. 335.2 para remitir expresamente a los supuestos del art. 
334, "avala la interpretación que hacemos en el sentido de que hasta dicha norma, los hechos enjuiciados no integraban el tipo delictivo".

En el periodo de referencia, continúa siendo objeto de análisis en la jurisprudencia menor el alcance del art. 336 en cuanto a la potencialidad lesiva de los métodos empleados para la caza. Así, por ejemplo, la SAP de Tarragona 516/2017, de 10 de noviembre, revisa la evolución de la posición interpretativa de la sala en los supuestos de la modalidad de caza denominada "barraca". En este sentido, la Audiencia había venido afirmando la atipicidad de la conducta en esta modalidad de caza, por no entender asimilable su poder destructivo al del veneno o los medios explosivos, que provocan "de forma necesaria e irreversible la muerte de los especímenes afectados, lo que no cabe predicar del uso de la liga, el reclamo eléctrico o empleo posterior de disolvente, que si bien constituyen medios prohibidos por la normativa comunitaria y estatal, carecen de semejante potencialidad destructiva y sus efectos no aparecen irreversibles". Sin embargo, la reforma operada por LO 5/2010, de 22 de junio, que vino a modificar el art. 336 CP para incorporar al mismo los supuestos previstos en la Directiva 2008/99/CE relativa a la protección del medio ambiente mediante el Derecho penal, introdujo en la conducta típica los medios 'no selectivos', junto a los propiamente destructivos. En este sentido, expone la resolución que "la caza de 'zorzales o tordos' con pegamento o 'liga', tal y como se organiza mediante el método de la 'barraca', no permite evitar la captura de aves de otras especies. Por ello, la caza con 'barraca' se basa en un método no selectivo, por cuanto cualquier tipo de ave puede engancharse a la liga y ser capturada, y su eficacia 'no selectiva' es de proporción similar al veneno o explosivo hasta el punto que no es posible controlar ni la clase ni el número de aves que en un determinado momento puede llegar a caer por efecto de la 'liga'”. En consecuencia, señala la Audiencia que "replanteándonos nuestro anterior posicionamiento en función de la modificación legal, consideramos que con la nueva redacción el método de caza conocido como 'barraca' puede integrarse en la conducta típica del art. 336CP." Con todo, y aun considerar típica la conducta por el empleo de un medio no selectivo, la sentencia concluye con la absolución del acusado por un error en la valoración de la prueba, entendiendo que la condición de propietario de la finca donde se ubicaba la 'barraca' no resulta suficiente para desvirtuar la 
presunción de inocencia y fundamentar la autoría del delito. En este sentido, el tribunal considera que el hecho de que los agentes rurales no encontraran a nadie en el interior de la barraca, que el reclamo eléctrico no estuviera en funcionamiento y que no se hallaran aves en su interior sino únicamente plumas procedentes de una caza anterior, no permite concluir que el propietario hubiera cazado anteriormente o tuviera conocimiento o autorizara que otros lo emplearan. Asimismo, tampoco se condena al acusado por el delito de desobediencia por el que venía siendo imputado por su negativa a entregar a los Agentes rurales el reclamo eléctrico. El tribunal argumenta al respecto que no puede atribuirse especial gravedad al incumplimiento pues en la medida en que el mismo no funcionaba, su no entrega no tuvo efecto alguno en impedir la continuidad de la caza.

En otro orden de cosas, en este periodo la jurisprudencia ha abordado supuestos de malos tratos injustificados a animales. En este sentido, la SAP de Madrid 89/2018, de 9 de febrero, mantiene la condena de seis meses de prisión e inhabilitación para el ejercicio de profesión, oficio o comercio que tenga relación con los animales impuesta por concurrencia del tipo previsto en el art. $337 \mathrm{CP}$. En el caso concreto, la conducta delictiva es una conducta omisiva consciente y voluntaria que afecta a la vida, salud o integridad del animal: "si se hubiera tratado, simplemente, como dice el recurrente, de una mera impericia en la educación del animal, no se hubieran producido las graves consecuencias de su trato, o mejor, 'maltrato', ya que éste fue debido tanto a la duración de la técnica de contención aplicada como a su aplicación consistente en sujetarse con una cadena al cuello de modo tan prieto que le produjo un hinchazón o abultamiento, de $25 \mathrm{cms}$ de diámetro perceptible para cualquiera". El tribunal no acepta como justificación el que pudiera tratarse de un perro conflictivo, lo que en todo caso no pudo probarse, pues si su dueño no podía hacerse cargo de él, debería haberlo devuelto a la Sociedad de la que lo adoptó.

En la misma línea resuelve la SAP de Madrid 722/2017, de 14 de diciembre, que considera que haber dejado encerrados dos perros de propiedad solos y abandonados, sin comida ni agua, causándoles así la muerte, no puede tener encaje en el delito leve del art. 337bis CP (antigua falta del art. 631.2CP) sino en el tipo penal del 337 CP, en su redacción dada por la LO 5/2010, atendiendo a 
la fecha de los hechos, y valorando la concurrencia de la posición de garante que permite admitir la comisión por omisión. Interesante resulta también en esta resolución la valoración de la sala respecto de la concurrencia de las dos muertes que los magistrados estiman que hubieran podido calificarse como dos delitos en concurso ideal, y no como un solo delito -aunque continuado- como pretendía el Ministerio Fiscal. La condena es finalmente por un delito de maltrato por no poder agravar la Sala, la calificación penal del Ministerio fiscal. 